\title{
Update on the Management of Diabetes during Ramadan Fast for Healthcare Practitioners
}

\author{
Rathor MY, Mohammad Fauzi AR, Omar AM
}

Department of Internal Medicine, Kulliyyah of Medicine, International Islamic University Malaysia

\begin{abstract}
Fasting during the month of Ramadan is one of the five pillars of Islam, a recurring annual ritual, which is passionately practiced by most Muslims across the world. It is obligatory on every healthy Muslim; however, the Qur'an and Islamic teachings specifically exempt people with acute or chronic illnesses from this duty, especially if it might have harmful consequences. Muslims with diabetes are exempted from fasting, but many of them still fast during Ramadan, for their personal convictions as revealed by EPIDIAR study which showed that $43 \%$ of patients with type 1 diabetes and 79\% with type 2 diabetes fasted during Ramadan. Muslims constitute about a quarter of the world's population who are spread all over the globe. It is inevitable that health care issues peculiar to them will be encountered worldwide and health care providers will have to counsel them regarding medications and whether it is safe to undertake the fast. This paper is an update on the management of Ramadan fasting based on current evidence from published literature and expert opinions.
\end{abstract}

KEYWORDS: Diabetes, exemption, hypoglycaemia, Ramadan, Saum

\section{INTRODUCTION}

Fasting is an important religious ritual which is prescribed by many religions of the world. For Muslims it is one of the commandments of Allah Subhanaho wa Ta'ala (SWT) as decreed in the holy Qur'an; "O you who believe! Fasting is prescribed for you as it was prescribed for those before you in order that you might learn piety". ${ }^{1}$ This verse was revealed in the seventh century Hijra and according to this verse "those before you" implies that there is no religion in which fasting was not prescribed. It is mentioned in the Bible, in the Old Testament and the New Testament, the Qur'an, the Mahabharata, and the Upanishads. Besides religion, it has been used in medicine for weight management, for rest of the digestive tract and for lowering lipids. Islamic fasting (Saum) goes beyond the mere physical act of abstinence from food and water but also refraining from all vices and evils committed by us consciously or unconsciously. Every year, more than one billion Muslim adults, fast worldwide during the holy month of Ramadan, the ninth lunar month of the Islamic calendar (Hijra). Since the onset of

\section{Corresponding author:}

Prof. Dr. Mohammad Yousuf Rathor

Department of Internal Medicine

International Islamic University Malaysia

Kulliyyah of Medicine

IIUM Kuantan

Tel: 09-5706293

Fax: 09-5177631

Email:drmyrathor@yahoo.com
Ramadan is confirmed by the sighting of the new moon, or by the completion of thirty days of Sha'ban, its exact timing varies from location to location. It typically lasts for 29-30 days; dates vary from year to year because the Islamic calendar begins 10 to 11 days earlier each year than solar calendar and thus Ramadan occurs during different seasons of the year. This seasonal shift dramatically impacts on the daily fasting time which varies in length depending on the geographical location and season. While the average fasting period during Ramadan is 12 hours, ${ }^{2}$ it can vary from 11 to 18 hours. ${ }^{3}$ As currently Ramadan falls in the summer months, the number of fasting hours will progressively increase in the northern hemisphere. Moreover, latitudinal distance from the equator also substantially impacts on daily fasting time. In the UK a fast can last between 10 and 19 hours, while in Malaysia, the average duration of fasting is about 13 hours. During fasting, Muslims are obliged to refrain from food, oral medications, drinking, smoking, and sexual activity after the break of dawn (Sahoor) until sunset (Iftar).

Ramadan fasting is obligatory (fard) for every healthy Muslim adult. Being one of the five pillars of Islam, failure to observe it without reasonable excuses is a severely punishable sin. However those who are acutely ill,* the old and frail, insane people, menstruating women, * pregnant and nursing mothers* and travellers* are exempted. This exemption also applies to people with chronic illnesses like diabetes mellitus, especially those who are potentially at risk of harmful consequences because of fasting. ${ }^{4}$ As stated in the Qur'an; “....Allah intends every facility for you; He does not want to put you to difficulties. (He wants you) to complete the prescribed period and to glorify Him in that. He has guided you; and perchance 
you shall be grateful." ${ }^{5}$ ("these cases are exempted temporarily and must fast at a later date, a day for a day, but if they are unable to do so then they can compensate by giving alms to the poor. People who are travelling a distance of about fifty miles or more may break the fast temporarily during their travel and make up for it in later days, but it is preferable to keep the fast, if they can without causing extraordinary hardship to them).

The prevalence of diabetes is rapidly rising in most Islamic countries, as in the rest of the world. Diabetics who fast are potentially liable to several adverse metabolic risks which may increase with longer fasting periods. ${ }^{6-9}$ Therefore they are exempted as Islam encourages the maintenance of good health, even at the expense of fasting during Ramadan. However many people with diabetes often loathe to accept the exemption because of the status of the Ramadan fast, as revealed by a recent multi-centric survey among diabetic patients (EPIDIAR study) $(n=12914)$ which showed that $43 \%$ of patients with type 1 diabetes (T1DM) and $79 \%$ of type 2 diabetes (T2DM) fasted during Ramadan. ${ }^{8}$ Further evidence shows that most patients do not consult their physicians as they feel that the physician is very likely to prohibit fasting. They adjust their medication to fit in with the times when eating is allowed and often end up with acute complications. ${ }^{8} \mathrm{~A}$ recent questionnaire survey conducted in Pakistan found that out of 453 diabetic subjects, 327 (72.2\%) fasted during the month of Ramadan, the vast majority had T2DM (96.3\%) and subjects fasted for an average of 25 days in Ramadan. ${ }^{10}$ These results have prompted authorities all around the world, especially in Muslim majority countries, to update recommendations and guidelines on the management of diabetes during Ramadan.

The issue of Ramadan fasting and diabetes has been discussed in previous review articles and various conference proceedings, but there had been no consensus opinion on the issue due to lack of harmony between medical and religious advice until the decree issued at the meeting of the Council of the International Islamic Fiqh Academy of the Organization of Islamic Conference at its 19th session held in UAE in 2009, which included eminent Muslim clerics and diabetes experts. ${ }^{4}$ Since Muslims are spread all over the globe, health care issues peculiar to them will inevitably be encountered worldwide, and health care providers will have to deal with and accommodate their health needs. Therefore it is important for them to be well acquainted with evidence-based practice of Ramadan fasting and closely liaise with their Muslims diabetic patients who want to observe fast, so that they do so as safely as possible. Further in recent years therapeutic options for diabetes have expanded, with the introduction of new therapeutic agents and new technologies, some of which have shown potential therapeutic benefit during Ramadan fasting. In this paper we aim to provide a consensus update based on recommendations from this landmark conference, expert opinions as well as introduction of new medications.

\section{PATHOPHYSIOLOGICAL CHANGES DURING FASTING}

Following a usual meal, the amount of glucose available from carbohydrate breakdown often exceeds the cellular needs for glucose. Among normal healthy individuals this excess glucose is stored in the liver in the form of glycogen, fat, and structural proteins which serves as a ready reservoir for future use. Insulin is the primary hormone involved in this process. ${ }^{11}$ Body enters into a fasting state eight hours or so after the last meal. When the circulating levels of glucose start falling, insulin production by islet beta cells is reduced while there is an increase in the levels of the counter regulatory hormones glucagon and catecholamines. Glucagon production by alpha cells stimulates breakdown of glycogen stored in the liver and at the same time gluconeogenesis is augmented. ${ }^{12}$ Low levels of insulin also lead to increased fatty acid release from adipocytes, which can be xidized to generate ketones to be utilized as alternative fuels by the body organs, thus sparing glucose to be utilized by glucosedependent organs, like the brain and erythrocytes. During fasting the body's response depends on the length of the continuous fast. It is only with a prolonged fast of many days to weeks, that the body eventually turn to protein for energy. As the Ramadan fast only extends from dawn till dusk, there is ample opportunity to replenish energy stores at Sahoor and iftar meals. This provides a progressive gentle transition from using glucose to fat as the main source of energy, which aids weight loss and in the long run reduces one's cholesterol levels. After a few days of fasting, higher levels of endorphins appear in the blood resulting in a better level of alertness and an overall feeling of general mental well-being. This intricate balance between levels of circulating insulin and the counter-regulatory hormones, which maintain glucose levels within a physiological range, is disturbed in people with diabetes. Patients with T1DM and those with insulin deficiency may have excessive glycogenolysis, gluconeogenesis and ketogenesis during fast, leading to hyperglycaemia and ketoacidosis. ${ }^{12}$

The literature review indicates that fasting in Ramadan is safe in young healthy subjects as well as in T2DM patients with education and proper diabetic management. ${ }^{13-15}$ However a study among T2DM patients treated with oral hypoglycaemic agents showed four-fold increase of hypoglycaemic episodes during Ramadan fasting, compared with before fasting. ${ }^{4}$ Similarly EPIDIAR study revealed that hypoglycaemia increased about five-fold in patients with T1DM and 7.5 -fold in patients with T2DM. 8 Some studies have revealed that Ramadan fasting did alter biochemical parameters in patients with T2DM like substantial weight loss, signs of dehydration, raised serum concentrations of uric acid and cholesterol ${ }^{12,15,16}$ while in non-diabetic individuals, 
fasting was associated with reduction in plasma triglyceride and plasma LDL-cholesterol. ${ }^{17-19}$

\section{MEDICAL BASIS FOR FIQH RULINGS ON FASTING IN DIABETES}

The consensus during the Organization of the Islamic Conference (OIC) summit ${ }^{4}$ has categorized fasting diabetics into four categories, in line with the expert recommendations published in 2005. ${ }^{20}$ The categories are as follows. ${ }^{4}$

Category 1: Very high risk of serious complications
Type 1 diabetes (T1DM)
- $\quad$ Severe hypoglycaemia within the last 3
months prior to Ramadan
Patients with a history of recurrent hypogly
caemia or hyperglycaemia
Patients with lack of hypoglycaemia
awareness
Patients with sustained poor glycaemic
control
Diabetic ketoacidosis or hypoglycaemic coma
during the three months prior to Ramadan
Diabetes with other acute illness
Patients who have obligation to undertake
hard physical labour
- Women with diabetes during pregnancy
Patients on chronic dialysis

\section{Category 2: High risk of complications}

- $\quad$ Patients with poor glycaemic control (blood glucose levels of $10.0-16.5 \mathrm{mmol} / \mathrm{L}$ ) or high $\mathrm{HbA} 1 \mathrm{C}(\geq 10 \%)$

- $\quad$ Patients with renal insufficiency

- $\quad$ Patients with advanced macro vascular complications

- $\quad$ People living alone who are treated with insulin or oral insulin secretagogues

- $\quad$ Patients living alone with co-morbid conditions that present additional risk

- $\quad$ Old age with ill health

- $\quad$ Patients receiving treatment that may interfere with their cognitive function.

\section{Category 3: Moderate risk of complications \\ - Well-controlled patients treated with appropriate oral hypoglycaemic agents}

\section{Category 4: Low risk of complications}

- Well-controlled diabetic patients treated with diet alone, metformin, or a thiazolidinedione

Key: HbA1C = glycated haemoglobin

The Fiqh rule for persons in categories 1 and 2 is that they should not fast while the ruling for those in categories 3 and 4 is that they should fast. Pregnant women should also be strongly advised not to fast because of the evidence of foetal and maternal risk with poor glycaemic control. ${ }^{20,21}$

\section{Option of not fasting}

Ramadan is a blessed month for believers; and has a distinctive place amongst other months of the year. Diabetic Muslims often want to fast to share the blessing of this holy month. However there are several verses in Holy Qur'an that explicitly forbid acts that are harmful and injurious to one's health.

"And let notyourownhands throwyouintodestruction"22 "Do not destroy one another: for, behold, God is indeed a dispenser of grace unto you." 23

"God intends every facility for you, he does not want to put you into difficulties" 5

In the light of these verses, any Muslim who is sick, or who is potentially at risk of adverse events due to fasting, should not fast. Further, if a person is advised by a trusted health care professional that fasting is harmful to his health, then that person is exempted from fasting. ${ }^{4}$ Diabetic Muslims should realise that they don't transgress divine laws by not fasting. Further, to get the blessings of the Ramadan they can do a lot: pray as much as possible, seek for Laylat alQadr (the night of power) during the last 10 days of Ramadan, increase study and recitation of the Qur'an, and feed someone who cannot afford, exchange family and social visits and organize community events to raise money for charity.

\section{STRATEGIES TO ENSURE SAFETY OF DIABETICS WHO INSIST TO FAST}

The diabetic patients who wish to fast need preRamadan counseling for assessment, education, motivation, dietary and drug adjustment. Pre-Ramadan Medical Assessment: All diabetic patients who wish to fast during Ramadan should undergo medical assessment ideally 2 months before Ramadan with specific attention to their overall physical well-being, metabolic control, blood pressure, and lipids. Appropriate blood tests along with HbA1c levels, lipids, and renal function should be ordered and evaluated. If the risks of hypoglycaemia or hyperglycaemia are high they should be advised not to fast. Any possible changes to their drug regime which are deemed necessary should be made at this visit to facilitate safe fasting. Education and motivation: Physicians need to educate them individually, ideally along with their family members concerning the potential risks during fasting and recognition of warning symptoms of dehydration, hypoglycemia and other possible complications. They should have the appropriate blood glucose monitoring equipment and know how to check their sugar levels and how to respond appropriately to cut off points considered high or low levels of blood glucose. They must be told that feeling dizzy, sweaty and disorientated may all suggest low blood glucose, which can be dangerous if untreated as it may lead to fainting or fits. They should be reminded to break the fast as soon as any such symptoms are noted as well as in case they encounter any symptoms of acute 
illness. Blood glucose levels should be monitored more frequently during Ramadan, especially in the first few days at pre Sahoor, 3 hours after Sahoor, pre Iftar and 3 hours after Iftar to help them in adjusting their medication if needed. They should be told that monitoring of blood glucose does not invalidate the fast.

During Ramadan Muslims consume a greater variety of foods compared with the rest of the year. A dietary plan, based on metabolic, nutritional and lifestyle requirements, should be individually developed for each diabetic patient. Further it is a common practice to host Iftar parties and share food with others during this month-a common way of hospitality. These traditionally rich foods present a risk of hyperglycaemia and weight gain for these patients. They should be encouraged to maintain their good dietary habits and resist any temptation to consume excess food at Iftar or Sahoor because such a lifestyle contradicts the principal aim and spirit of Ramadan. Nutritional compliance during such times although difficult, warrants repeated counselling to achieve a safe fast. The following dietary guidelines should be recommended.

- $\quad$ Consume foods rich in complex carbohydrates which release energy slowly such as barley, wheat, oats, beans, wholemeal flour, and unpolished rice at Sahoor.

- Limit consumption of fried foods, processed foods, and commercially prepared baked goods (donuts, cookies, crackers, etc).

- Include fruits, vegetables, lentils (dal) and yoghurt in meals at Iftar and Sahoor. Fruits such as bananas are a good source of potassium, magnesium and carbohydrates.

- Limit animal products like egg yolks, cheeses, whole milk, cream and ice cream. Fish, lean meat and poultry can be taken.

- $\quad$ Have the Sahoor meal just before dawn, not at midnight. This will result in more balanced blood glucose levels and prevent from hypoglycaemic events.

- $\quad$ Consume refined carbohydrates or fastdigesting foods at Iftar to restore

blood glucose levels rapidly. Dates are an excellent source of sugar, fibre, carbohydrates, potassium and magnesium and have been recommended since the days of the Prophet Mohammed (SAW) as a good way of breaking the fast. Limit the amount of sweets such as cakes to avoid swift upsurge in blood glucose.

- $\quad$ Drink sufficient fluids between Iftar and sleep to avoid dehydration, renal failure and thrombotic events. Avoid large amounts of caffeine-containing beverages especially at Sahoor.

- $\quad$ Encourage patients to continue with their regular daily physical activity, but avoid rigorous exercise which may lead to hypoglycaemia.

\section{RAMADAN AND MEDICATION}

The following therapeutic regimens have been suggested by the American Diabetes Association (ADA) workgroup (Level 4). ${ }^{20}$

Therapeutic options for T1DM

1. NPH insulin BD and short acting insulin before meals.

2. Ultralente BD with short acting insulin before meals.

3. Insulin glargine OD or insulin determir BD.

4. Intermediate acting insulin BD with insulin lispro before meals.

5. Subcutaneous insulin pump.

Recommended changes for T2DM

1. Diet control - to take 2 to 3 smaller meals between Iftar and sahoor and modify exercise.

2. Metformin - 2/3 daily dose at Iftar, $1 / 3$ daily dose at Sahoor.

3. Glitazones - no change is required.

4. Sulphonylureas - treatment should be individualized and used with caution. The options are:
a. Once daily after Iftar or
b. Half the usual morning dose at Sahoor and full dose at the Iftar.

5. Short acting secretagogues - may be safer than sulphonylureas

6. Premixed insulin 70/30 - Usual morning dose at Iftar and half the usual evening dose at Sahoor

7. Consider changing to glargine or determir plus lispro.

Studies of therapeutic options during Ramadan fasting have been done almost exclusively in T2DM. Only one trial was conducted on T1DM. ${ }^{24}$ Ideally T1DM patients should not fast and if they do, it is their personal decision. They must be made aware of the associated risks and they require very careful supervision and monitoring. They should not go for tight control; a level of glucose of $8-9 \mathrm{mmol} / \mathrm{l}$ is acceptable, with the aim to keep them out of trouble i.e. avoiding hypoglycaemia and ketoacidosis. T2DM with co-morbid illnesses or those unwilling or unable to monitor their blood glucose should be strongly discouraged from fasting.

T2DM who are doing well on diet control alone, can fast. Those treated with oral hypoglycemic agents such as thiazolidinedione or metformin have significantly lower risk of hypoglycemia as they act by increasing insulin sensitivity rather than compounds that act by increasing insulin secretion. Individuals treated with Metformin alone may safely fast, however dose should be split such that two thirds of the dose is taken at Iftar and one third at Suhoor. ${ }^{25}$ Patients, who are on extended-release Metformin preparations, should take it once at Iftar. 
Thiazolidinediones: Currently Pioglitazone is the only agent in use from this class due to the unfavorable safety profile of Rosiglitazone. It can be taken with or without food (at Sahoor and Iftar) and there is no need to change the dose. It can also be added for those with suboptimal glycaemic control.

Short-acting insulin secretagogues: such as Repaglinide or Nateglinide increase endogenous insulin secretion and are useful because of their short duration of action. They have been shown to be safe as compared with sulphonylureas. The addition of Repaglinide to T2DM poorly controlled with Metformin alone, can provide better overall glycaemic control. a-Glucosidase inhibitors: such as Acarbose and Voglibose slow the absorption of carbohydrates when taken with the meal and are particularly useful during Ramadan, as they are not associated with an independent risk of hypoglycemia and their use does not necessitate any special precautions. They decrease postprandial insulin needs, but have limited efficacy and cause gastrointestinal side effects, especially flatulence. ${ }^{26}$

The dipeptidylpeptidase-4 (DPP4) inhibitors: such as Vildagliptin and Sitagliptin are new oral hypoglycaemic agents which block dipeptidylpeptidase-4, increase incretin levels which inhibit glucagon release and stimulate insulin secretion. They provide an effective and safe therapeutic option during Ramadan. They can be administered either alone or in combination with Metformin or sulfonylurea's. ${ }^{27,28}$

Glucagon-like peptide-1 mimetics (GLP1 mimetics): Exenatide and Liraglutide are incretin mimetic which are given by subcutaneous injections and are potentially safe during Ramadan. They stimulate glucose dependent insulin secretion from beta-cells only when the glucose level is above the normal range; they cease to act between meals when glucose levels are lower, thereby eliminating the risk of hypoglycemia. Currently there are no published studies of their use during Ramadan, although in non-Ramadan studies, hypoglycemic events occurred primarily in patients taking a sulphonylurea. ${ }^{29}$ Exenatide with its short half-life of 2 hours can be dosed before meals to minimize appetite and promote weight loss and has no substantial effect on fasting glucose.

Among the sulfonylureas, Gliclazide MR (modified release) and Glimepride can be safely used during Ramadan, but Glibenclamide should be avoided due to the associated risk of hypoglycaemia. ${ }^{21,30}$ In selected patients with T1DM and T2DM, the longacting insulin analogues Glargine and Detemir, as well as the premixed insulin analogues, can be used with minimal risk of metabolic derangement. Insulin pumps can potentially enable safe Ramadan fasting as they provide continuous insulin delivery over $24 \mathrm{~h}$ with basal infusion rates programmed and individualized for each patient. Patients self-administer boluses of insulin with meals or at times of hyperglycemia, often with mathematical support from the pump. This method of insulin delivery works very well for highly motivated patients, but requires significant patient education, meticulous monitoring and supervision by heatlh care provider. In a recent small study in 5 Saudi adolescents with T1DM (age between 15-19 years, mean duration of diabetes of 7 years) the use of subcutaneous insulin infusion (CSII) during Ramadan was associated with improvement in glycaemic control and less hypoglycemia in comparison with conventional insulin therapy. ${ }^{31}$ However further larger studies of insulin pump use during Ramadan are needed.

\section{CONCLUSION}

Ramadan fasting is an important pillar of the Muslim faith and most people with diabetes will continue to fast during Ramadan. It is important that healthcare professionals are well acquainted with evidence-based practice of Ramadan fasting. Further, they should consider using new therapeutic agents and technologies which have shown potential therapeutic benefit during Ramadan fasting.

\section{REFERENCES}

1. The Glorious Qur'an, Chapter 2, Verse 183.

2. Aksungar FB, Eren A, Ure S, Teskin O, Ates G. Effects of intermittent fasting on serum lipid levels, coagulation status and plasma homocysteine levels. Ann Nutr Metab 2005; 49: 77-82.

3. Aadil N, Houti IE, Moussamih S. Drug intake during Ramadan. BMJ 2004; 329:778-782.

4. Beshyah SA. Fasting during the month of Ramadan for people with diabetes: Medicine and Fiqh United at last. Ibnosina J Med Biomed Sci 2009; 1:58-60.

5. The Glorious Qur'an, Chapter 2, Verse 185.

6. Bravis V, Hui E, Salih S, et al. Ramadan Education and Awareness in Diabetes (READ) programme for Muslims with type 2 diabetes who fast during Ramadan. Diabetes Med 2010; 27: 327-31.

7. Uysal AR, Erdogan MF, Sahin G, et al. Clinical and metabolic effects of fasting in 41 type 2 diabetic patients during Ramadan. Diabetes Care 1998; 21:2033-4.

8. Salti I, Bénard E, Detournay B, et al. EPIDIAR study A population-based study of diabetes and its characteristics during the fasting month of Ramadan in 13 countries. Diabetes Care 2004; 27:2306-11.

9. Katibi IA, Akande AA, Bojuwoye BJ, Okesina AB. Blood sugar control among fasting Muslims with type-2 diabetes mellitus in Ilorin. Niger $\mathrm{J}$ Med 2001; 10:132-4.

10. Ahmadani MY, Riaz M, Fawwad A, et al. Glycaemic trend during Ramadan in fasting diabetic subjects: A study from Pakistan. Pak J Biol Sci 2008; 11:2044-7.

11. Herber D. Endocrine response to starvation, malnutrition and illness. In: De Groot LY, ed. Endocrinology. 3rd ed. Philadelphia: Sanders, 
1995.

12. Cryer PE, Davis SN, Shamoon H. Hypoglycemia in diabetes (Review). Diabetes Care 2003; 26:1902-12.

13. Roky R, Houti I, Moussamih S, Qotbi S, Aadil N. Physiological and chronobiological changes during Ramadan intermittent fasting. Ann Nutr Metab 2004; 48:296-303.

14. Khatib FA, Shafagoj YA. Metabolic alterations as a result of Ramadan fasting in non-insulindependent diabetes mellitus patients in relation to food intake. Saudi Med J 2004; 25:1858-63.

15. Yousuf RM, Fauzi ARM, How SH, Shah A. Metabolic changes during Ramadan fasting in normal people and Diabetic patients. International Medical Journal 2003; 2(2).

16. Khaled BM, Belbraouet S. Effect of Ramadan fasting on anthropometric parameters and food consumption in 276 type 2 diabetic obese women. Int J Diabetes Dev Ctries 2009; 29:62-8.

17. Shariatpanahi ZV, Shariatpanahi MV, Shahbazi S, Hossaini A, Abadi A. Effect of Ramadan fasting on some indices of insulin resistance and components of the metabolic syndrome in healthy male adults. Br J Nutr 2008; 100 : 147-51.

18. Haghdoost AA, Poorranjbar M. The interaction between physical activity and fasting on the serum lipid profile during Ramadan. Singapore Med J 2009; 50:897-901.

19. Fakhrzadeh $H$, Larijani B, Sanjari $M$, Baradar- Jalili R, Amini MR. Effect of Ramadan fasting on clinical and biochemical parameters in healthy adults. Ann Saudi Med 2003; 23:223-26.

20. Al Arouj M, Ibrahim M, Hassanein M, et al. Recommendations for management of diabetes during Ramadan. Diabetes Care 2005; 28:12052311.

21. Metzger BE, Lowe LP, Dyer AR, et al. Hyperglycaemia and adverse pregnancy out comes. N Eng J Med 2008; 358:1991-2002.

22. The Glorious Qur'an, Chapter 2, Verse 195.

23. The Glorious Qur'an, Chapter 4, Verse 29.

24. Kadiri A, Al-Nakhi A, El-Ghazali S, et al. Treatment of type I diabetes with insulin lispro during Ramadan. Diabetes Metab 2001; 27:482-6.

25. Al-Arouj M, Assaad-Khalil S, Buse J, et al. Recommendations for management of diabetes during Ramadan: update. Diabetes Care 2010; 33:1895-902.

26. Van de Laar FA, Lucassen PL, Akkermans RP, et al. Alpha-glucosidase inhibitors for type 2 diabetes mellitus. Cochrane Database Syst Rev 2005;2:CD003639.

27. Drucker DJ, Sherman SI, Gorelick FS, et al. Incretin-based therapies for the treatment of type 2 diabetes: evaluation of the risks and benefits. Diabetes Care 2010; 33:428-33.

28. Devendra D, Gohel B, Bravis V, et al. Vildagliptin 